\title{
Early detection of COPD in general practice
}

This article was published in the following Dove Press journal:

International Journal of Chronic Obstructive Pulmonary Disease

27 January 2011

Number of times this article has been viewed

\section{Charlotte Suppli Ulrik' \\ Anders Løkke ${ }^{2}$ \\ Ronald Dahl ${ }^{3}$ \\ Jens Dollerup ${ }^{4}$ \\ Gert Hansen ${ }^{4}$ \\ Patrick Hagge Cording ${ }^{5}$ \\ Klaus Kaae Andersen ${ }^{5}$ \\ On behalf of the TOP study group \\ 'Department of Heart and Lung Diseases, Hvidovre University Hospital, Hvidovre; ${ }^{2}$ Department of Internal Medicine, Silkeborg Hospital, Silkeborg; ${ }^{3}$ Department of Respiratory Diseases, Århus University Hospital, Århus; ${ }^{4}$ Pfizer Aps, Ballerup; ${ }^{5}$ Informatics, Section for Statistics, Technical University of Denmark, Lyngby, Denmark}

Correspondence: Charlotte Ulrik Virum Overdrevsvej 13, DK-2830 Virum, Denmark Email csulrik@dadlnet.dk
Background and aim: Early detection enables the possibility for interventions to reduce the future burden of COPD. The Danish National Board of Health recommends that individuals $>35$ years with tobacco/occupational exposure, and at least 1 respiratory symptom should be offered a spirometry to facilitate early detection of COPD. The aim, therefore, was to provide evidence for the feasibility and impact of doing spirometry in this target population.

Methods: Participating general practitioners (GPs) $(n=335 ; 10 \%$ of the Danish GPs) recruited consecutively, subjects with $>35$ years exposure, no previous diagnosis of obstructive lung disease, and at least 1 of the following symptoms: cough, dyspnea, wheezing, sputum, or recurrent respiratory infection. Data on age, smoking status, pack-years, body mass index (BMI), dyspnea score (Medical Research Council, MRC), and pre-bronchodilator spirometry ( $\mathrm{FEV}_{1}$, $\mathrm{FEV}_{1} \%$ predicted, $\left.\mathrm{FEV}_{1} / \mathrm{FVC}\right)$ were obtained.

Results: A total of 3.095 (51\% females) subjects was included: mean age 58 years, BMI 26.3, and 31.5 pack-years. The majority of subjects $(88 \%)$ reported MRC score 1 or 2 . FEV 1 /FVCratio $\leq 0.7$ was found in $34.8 \%$ of the subjects; the prevalence of airway obstruction increased with age and decreased with increasing BMI, and was higher in men and current smokers. According to the level of $\mathrm{FEV}_{1}, 79 \%$ of the subjects with airway obstruction had mild to moderate COPD.

Conclusions: More than one-third of the recruited subjects had airway obstruction $\left(\mathrm{FEV}_{1} /\right.$ FVC $<0.7$ ). Early detection of COPD appears to be feasible through offering spirometry to adults with tobacco/occupational exposure and at least 1 respiratory symptom.

Keywords: COPD, spirometry, general practice, airway obstruction, screening

\section{Introduction}

COPD is a common disease, which causes substantially impaired quality of life and increased risk of premature death. Tobacco smoking is the most important risk factor for COPD in up to $90 \%$ of patients in Western societies, although environmental, occupational, and genetic factors also interact and play a role. ${ }^{1-3}$

In most cases COPD has its roots decades before the onset of symptoms and runs an insidious course over years, often with an undiagnosed initial phase. ${ }^{1,4,5}$ COPD is frequently diagnosed at a relatively late stage of the disease, probably because early symptoms of the disease are subtle and unrecognized due to individual perception and interpretation. ${ }^{5}$ Early symptoms of the disease may not be evident, although airflow obstruction is present on spirometry. Patients suffering from more severe COPD have substantial limitations in activities of daily living, leading to poor healthrelated quality of life and disability. Early recognition of cases may therefore have 
the potential to reduce the future burden of COPD for both morbidity and mortality. ${ }^{5}$

In Denmark, as in any country, general practitioners and family physicians (GPs) are on the frontline for prevention and early diagnosis of COPD. The GPs should therefore be encouraged to take the lead in implementing spirometry, as well as the recommendations of the updated treatment guidelines. In keeping with this, the Danish National Board of Health recommends that smokers/ex-smokers and individuals with relevant occupational exposure over 35 years with at least 1 respiratory symptom should be offered spirometry to facilitate early detection of COPD. ${ }^{6}$ This approach was recently adopted in the COPD guidelines generated by the Danish Society for General Practice. ${ }^{7}$

The aim of this general practice-based study was to investigate the feasibility for implementing the recommendation of spirometry in the defined risk population.

\section{Material and methods}

Denmark has approximately $3600 \mathrm{GPs}$, covering a population of 5.4 million. We aimed on a voluntary basis to include a representative sample comprising at least 200 GPs from all over Denmark. Written information about the project, as well as the invitation to participate, was distributed to all the interested GPs by the sponsoring companies' local representatives. Each of the participating GPs was expected to screen at least 30 consecutive subjects who attended the practice and fulfilled the eligibility criteria.

Subjects were eligible for the study provided they fulfilled the following inclusion criteria: 1 ) age $\geq 35$ years; 2 ) smoker/ ex-smoker or relevant occupational exposure; 3 ) $\geq$ one respiratory symptom (dyspnea, cough, wheeze, sputum, and/ or recurrent chest infections); and not the following exclusion criteria: 1) unable to perform spirometry; 2) previous diagnosis of obstructive lung disease (asthma and/or COPD) or other chronic respiratory disease.

The case record form (CRF) consisted of 2 parts: 1) a questionnaire filled in by the participant for age, gender, height, body weight, smoking status, daily tobacco consumption, years of smoking, airway symptoms (cough, dyspnea, wheezing, sputum, and recurrent lower airway infection), and severity of dyspnea (graded according to Medical Research Council, MRC; ${ }^{8}$ 2) data obtained by the GP in his/her own practice on spirometry $\left(\mathrm{FEV}_{1}\right.$, expressed in absolute value and as a percentage of the predicted value, $\mathrm{FVC}$, and $\mathrm{FEV}_{1} /$ FVC ratio), severity of COPD (graded according to GOLD ${ }^{9}$ ), the participants' wishes in relation to smoking cessation (including need for nicotine replacement therapy or prescribed medication), and the final decision whether or not further intervention is indicated. All data from the individual CRF were entered into a consolidated web-based database; and on registration the body mass index (BMI), $\mathrm{FEV}_{1} / \mathrm{FVC}$ ratio, severity of COPD (based on $\mathrm{FEV}_{1} \%$ predicted), and number of pack-years was automatically calculated. Consultants from the sponsoring companies performed quality control of the CRFs.

\section{Data analysis}

Data from individual participant's records were analyzed focusing on the defined outcome variables; only data for participants with complete CRFs (95.2\%) were included in the analyses. The $\mathrm{FEV}_{1}$ was expressed as the absolute value and also as a percentage of the predicted value, ${ }^{10}$ and the $\mathrm{FEV}_{1} / \mathrm{FVC}$ ratio as the absolute value. Predictors of an $\mathrm{FEV}_{1} / \mathrm{FVC}$ ratio $<0.7$ were identified by means of multiple logistic regressions with predictor variables for gender, age, BMI, and smoking status. Quantitative predictor variables were included using smoothing splines, and tested for possible nonlinearities. In all the statistical analyses a significance level of 5\% was adopted and significance of predictor variables was tested by means of the likelihood ratio test. The results were interpreted terms of odds ratios and visualized using nomograms. The statistical software $\mathrm{R}^{11}$ was used for the statistical analyses. The TOP project was accepted by the Danish College of General Practitioners.

According to the EFPIA code, ${ }^{12}$ and the Danish Association of the Pharmaceutical Industry (LiF), ${ }^{13}$ the present study was a noninterventional trial, and approval from the scientific ethical committee and the Danish Medicines Agency were not mandatory, but they were given all relevant study information. The study was approved by the Danish Data Protection Agency.

\section{Results}

A total of 335 GPs participated in the study, and 3095 individuals ( $49 \%$ males) with complete data were included in the analyses. A total of $65 \%$ of the study population $(62 \%$ males and $67 \%$ females) were current smokers, and 3\% were never smokers. Approximately $50 \%$ of the current smokers stated that they were not interested in quitting smoking, and no difference was observed between smokers with and without airway obstruction. Further characteristics of the enrolled subjects are given in Table 1.

The most common reported respiratory symptoms were dyspnea (66\%) and cough (63\%), whereas wheeze, sputum, and recurrent respiratory infection were reported by $21 \%, 31 \%$, 
Table I Characteristics of the enrolled subjects

\begin{tabular}{lll}
\hline & $\begin{array}{l}\text { Males } \\
(\mathbf{n}=1503)\end{array}$ & $\begin{array}{l}\text { Females } \\
(\mathbf{n}=1594)\end{array}$ \\
\hline Age $($ years $)$ & $58(36-90)$ & $57(36-88)$ \\
BMI $\left(\mathrm{kg} / \mathrm{m}^{2}\right)$ & $27(15-49)$ & $26(14-55)$ \\
Pack-years $(\mathrm{n})$ & $38(0.5-175)$ & $29(0.1-172)^{*}$ \\
\hline
\end{tabular}

Note: $* P<0.05$.

Abbreviation: BMI, body mass index.

and $14 \%$, respectively. The majority of subjects $(88 \%)$ reported dyspnea score 1 and 2, whereas $12 \%$ of the enrolled subjects reported dyspnea of such severity (MRC 3 to 5) that they fulfilled the criteria for referral to a hospital-based rehabilitation program. Almost half of the individuals (45\%) reported only 1 respiratory symptom, whereas $28 \%$ reported 2 symptoms.

Airway obstruction, defined as a $\mathrm{FEV}_{1} / \mathrm{FVC}$ ratio $\leq 0.7$, was found in $34.8 \%(n=1079)$ of the enrolled subjects. The prevalence of airway obstruction was increasing with age, but airway obstruction was also found in a substantial proportion of the subjects in the younger age groups (Figure 1). In the analysis, gender, age, BMI, and smoking status were all found to be significant predictors of $\mathrm{FEV}_{1} / \mathrm{FVC}$ ratio $\leq 0.7$. The prevalence of airway obstruction was higher for increasing age and decreasing BMI. Furthermore, the prevalence was also higher in men than in women, and in smokers than in ex-smokers and never smokers. The $95 \%$ confidence intervals for odds ratios of these risk factors are given in Table 2. A nomogram for the analysis obtained by the multiple regression model is given in Figure 2. From the nomogram, individual predictions can be obtained by adding

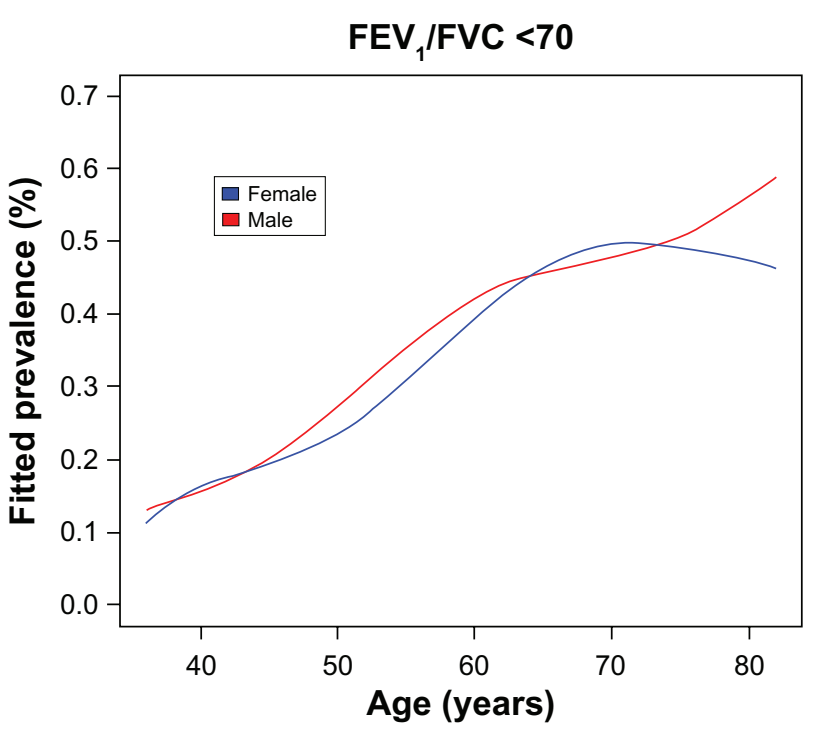

Figure I Estimated age and gender specific prevalence of $\mathrm{FEV}_{\mathrm{I}} / \mathrm{FVC}$ ratio $\leq 70 \%$. the partial effect on each risk factor and using the sum to calculate the risk of having a $\mathrm{FEV}_{1} / \mathrm{FVC}$ ratio $<0.7$; furthermore, the relative importance of risk factors can be seen directly.

Further analysis of the data for the individuals with airway obstruction $(n=1078)$ showed that the level of $\mathrm{FEV}_{1} \%$ predicted in $28 \%$ and $51 \%$, respectively, fulfilled the criteria for mild and moderate COPD (Figure 3).

\section{Discussion}

Denmark has approximately $3600 \mathrm{GPs}$, covering a population of 5.4 million, and we aimed to include, on a voluntary basis, at least 200 GPs in the study from all over Denmark. However, the general interest for participating in the study exceeded our expectations, and a total of 335 GPs (almost $10 \%$ of the Danish GPs) agreed to participate, and included 3095 subjects in the study. As expected, not all of the enrolled GPs contributed subjects to the study sample, just as some of the participating GPs did not manage to enrol 30 subjects, but eventually more than 220 GPs contributed subjects with complete data for the study sample.

The present study demonstrated clearly that early detection of COPD is feasible in general practice by offering spirometry to individuals with relevant exposure and airway symptoms. Furthermore, the observed prevalence of airway obstruction was disturbingly high, but fortunately the majority of the subjects identified with airway obstruction appeared, as judged by the level of $\mathrm{FEV}_{1} \%$ predicted, to have mild to moderate COPD. Using this case finding approach may therefore provide an opportunity for early intervention aimed at improving prognosis.

Compared with previous reports from the Lung Health study ${ }^{14}$ and the study by Zielinski and Bednarek, ${ }^{15}$ the present study revealed a much higher prevalence of airway obstruction $(>30 \%)$, although the subjects included in the present study did not have a higher mean cumulative life-long tobacco exposure. Furthermore, studies by Miravitlles et $\mathrm{al}^{16}$ and Hansen et al ${ }^{17}$ have likewise reported a much lower prevalence of COPD, $10 \%$ and $12 \%$, respectively. These differences may be explained by differences in recruitment of subjects such as age, life-time tobacco exposure (pack-years), marketed type of cigarettes, genetics, differences in air pollution and environmental exposure, and/or pattern and availability of health care utilization. The case-finding design of offering spirometry to individuals with relevant exposure and at least 1 respiratory symptom used in the present study proved to be more cost-effective in general practice compared with previous reports. ${ }^{18}$ 
Table 2 Distribution of $\mathrm{FEV}_{1} / \mathrm{FVC}<70$ stratified on gender, smoking status, age, and BMI

\begin{tabular}{|c|c|c|c|c|}
\hline Risk factor & $\begin{array}{l}\text { FEV } \text { IFVC }<70 \\
\mathbf{N}(\%)\end{array}$ & $\begin{array}{l}\text { FEV } / \text { IFVC } \geq 70 \\
N(\%)\end{array}$ & 95\% Cl for OR & $P$-value \\
\hline \multicolumn{5}{|l|}{ Gender } \\
\hline Female & $527(33.1)$ & $1063(66.9)$ & & \\
\hline Male & 55I (36.6) & $954(63.4)$ & {$[1.01-1.38]$} & 0.039 \\
\hline Smoking & & $1290(64.5)$ & & \\
\hline Smoker & $713(35.5)$ & & & \\
\hline Ex-smoker & $343(34.6)$ & $647(65.4)$ & {$[0.64-0.91]$} & 0.002 \\
\hline Never smoker & $22(2 \mid .5)$ & $80(78.5)$ & {$[0.27-0.74]$} & 0.001 \\
\hline \multicolumn{5}{|l|}{ Age (years) } \\
\hline $36-48$ & I44 (I7.9) & $657(82.1)$ & & \\
\hline $49-58$ & $262(31.6)$ & $566(68.4)$ & & \\
\hline $59-66$ & $3 \mid 2(4 \mid .7)$ & $436(58.3)$ & & \\
\hline $67-90$ & $360(50.0)$ & $358(50.0)$ & {$[2.20-2.84]$} & $<0.001$ \\
\hline \multicolumn{5}{|l|}{ BMI $\left(\mathrm{kg} / \mathrm{m}^{2}\right)$} \\
\hline |4.4-23.| & $327(42.2)$ & 447 (57.8) & & \\
\hline $23.2-25.6$ & 301 (39.3) & $464(60.7)$ & & \\
\hline $25.7-28.7$ & $231(30.1)$ & $536(69.9)$ & & \\
\hline $28.8-55.0$ & $219(27.7)$ & $570(72.3)$ & {$[0.64-0.78]$} & $<0.001$ \\
\hline
\end{tabular}

Notes: The grouping of age and body mass index $(\mathrm{BMI})$ is based on quartiles. The $95 \%$ confidence intervals $(\mathrm{Cl})$ and $P$-values for odds ratios $(\mathrm{OR})$ were obtained from multivariate logistic regression. Female smokers were set as reference levels for the OR. The OR for age and BMI correspond to an increase in interquartile range.

A ratio of $\mathrm{FEV}_{1}$ to $\mathrm{FVC}$ of less $<0.7$ when measured after the administration of an inhaled bronchodilator is the spirometric criterion to define COPD, ${ }^{1,9}$ whereas no symptoms are needed. In the present study only prebronchodilator spirometry was performed, and some, most likely only a minority of the individuals identified with airway obstruction may have a post-bronchodilator $\mathrm{FEV}_{1} / \mathrm{FVC}$ ratio within the reference values. However, doing post-bronchodilator spirometry was beyond the scope of the present study. Furthermore, the validity of the present findings for the diagnosis of COPD is supported by the current UK National Institute for Clinical Excellence ${ }^{19}$ COPD guidance in which pre-bronchodilator spirometry values are used to diagnose and stage COPD. ${ }^{19,20}$

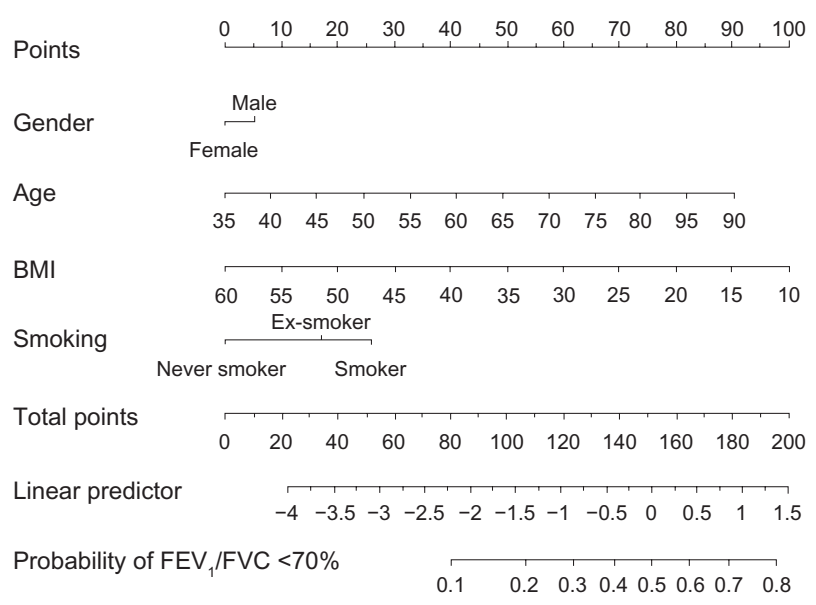

Figure 2 Nomogram used for predicting the probability of $\mathrm{FEV}, / \mathrm{FVC} \leq 70 \%$ The model reported in Table 2 has been used in constructing the nomogram.
Previous studies suggest that using a fixed ratio for $\mathrm{FEV}_{1} /$ FVC as the diagnostic criterion may overestimate the prevalence of COPD in the elderly and underestimate the prevalence in younger subjects. ${ }^{5,16}$ It has, therefore, in the Spanish/Latin America guidelines ${ }^{20}$ been suggested to use the lower limit of normal, ie, the bottom $5 \%$ of the normal distribution of $\mathrm{FEV}_{1} / \mathrm{FVC}$ in a healthy reference population, for the diagnosis of COPD. In keeping with most published COPD guidelines, we decided to use the fixed $\mathrm{FEV}_{1} / \mathrm{FVC}$ ratio, not least because this appears to be easier to handle as the diagnostic criterion in general practice.

In conclusion, the present study showed that early detection of COPD in general practice by offering spirometry to individuals with relevant exposure and airway symptoms is not only feasible, but identified a high proportion of individuals with airway obstruction. Furthermore, the majority of subjects

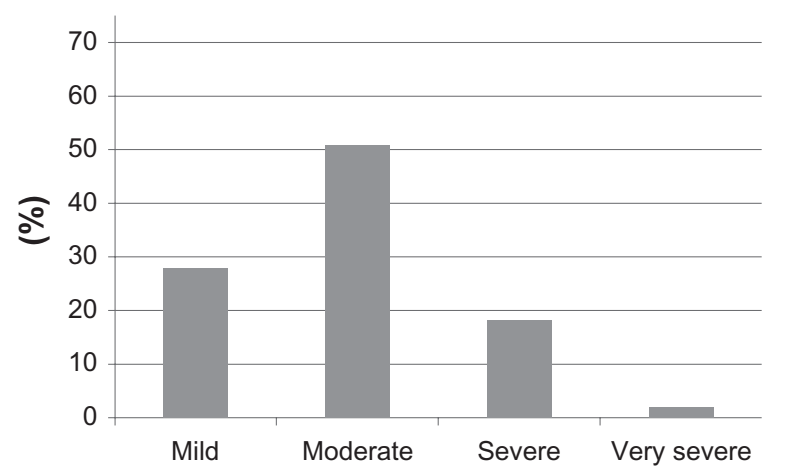

Figure 3 Distribution of enrolled subjects with airway obstruction ( $F E V_{1} / F V C \leq 70 \%$ ) $(n=1078)$ according to severity of COPD (based on FEV $\%$ predicted). 
with signs of COPD appeared to have mild to moderate disease, and secondary preventive measures may reduce the future burden of COPD, for both morbidity and mortality.

\section{Contributors}

As principal investigators CSU, AL, RD, JD, GH, PHC, and KKA had full access to all the study data, and take responsibility for their integrity and the accuracy of their analysis. CSU, AL, RD, JD, and GH participated in the study design, and supervised the study. PHC and KKA analyzed the data and provided the statistical expertise. CSU drafted the report, and the report was revised for important intellectual content by $\mathrm{AL}, \mathrm{RD}, \mathrm{JD}, \mathrm{GH}$, and KKA.

\section{Acknowledgment}

This study was sponsored by Boehringer Ingelheim and Pfizer Aps, Denmark.

\section{Disclosure}

As members of the steering committee of the TOP study, $\mathrm{CSU}, \mathrm{AL}$, and $\mathrm{RD}$ have received consulting fees from Boehringer-Ingelheim and Pfizer Aps, Denmark. JD and GH are employed by Pfizer Aps, Denmark. PHC and KKA declare that they have no conflicts of interests.

\section{References}

1. Celli BR, McNee W, ATS/ERS committee members. Standards for the diagnosis and treatment of patients with COPD: a summary of the ATS/ ERS position paper. Eur Respir J. 2004;23:932-946.

2. COPD - more than just tobacco smoke (editorial). Lancet. 2009; 374:663.

3. Blanc PD, Menezes AM, Plane E, et al. Occupational exposures and COPD: an ecological analysis of international data. Eur Respir J. 2009; 33:298-304.

4. Celli BR. Update on the management of COPD. Chest. 2008;133: 1451-1462.

5. Soriano JB, Zielinski J, Price D. Screening for and early detection of chronic obstructive pulmonary disease. Lancet. 2009;374:721-732.

6. KOL: Anbefalinger for tidlig opsporing, opfølgning, behandling, og rehabilitering [COPD: Recommendations for early detection, monitoring, treatment and rehabilitation; in Danish]. Danish National Board of Health; 2007.
7. Nielsen LM, Brorson S, Gorlen T, et al. KOL i Almen Praksis [COPD in General Practice; in Danish]. Danish College of General Practitioners; 2008.

8. Bestall JC, Paul EA, Garrod R, Granham R, Jones PW, Wedzicha JA. Usefulness of the Medical Research Council (MRC) dyspnoea scale as a measure of disability in patients with chronic obstructive pulmonary disease. Thorax. 1999;54:581-586.

9. Global Initiative for Chronic Obstructive Lung Disease. Global Strategy for Diagnosis, Management and Prevention of COPD. Guidelines available from the GOLD website www.goldcopd.com. Accessed February 2010.

10. Quanjer PH, Tammeling GJ. Summary of recommendations. Standardized lung function testing. Report Working Party, European Community for Coal and Steel. Bull Eur Physiopathol Respir. 1983; 19(suppl 5):7-20.

11. Ihaka I, Gentleman RR. A language for data analysis and graphics. J Comput Graph Stats. 1996;5:299-314.

12. EFPIA code on the promotion of prescription-only medicines to, and interactions with, healthcare professionals. European Federation of Pharmaceutical Industries and Associations (Council Directive 2001/ 83/EC). www.efpia.eu. Accessed February 11, 2010.

13. Lægemiddelindustriforeningen www.lifdk.dk. Accessed February 11, 2010.

14. Connett JE, Bjornsen-Benson WM, Daniels K. Recruitment of participants in the Lung Health Study II. Assessment of recruiting strategies: Lung Health Study Research Group. Control Clin Trials. 1993;14:38S-51S.

15. Zielinski J, Bednarek M; the Know the Age of Your Lung Study Group. Early detection of COPD in a high-risk population using spirometric screening. Chest. 2001;119:731-736.

16. Maravitlles M, Soriano JB, Garcia-Rio F, et al. Prevalence of COPD in Spain: impact of undiagnosed COPD on quality of life and daily life activities. Thorax. 2009;64:863-868.

17. Hansen JG, Pedersen L, Overvad K, Omland Ø, Jense HK, Sørensen HT. The prevalence of chronic obstructive pulmonary disease among Danes aged 45-84 years: population-based study. COPD. 2008;5: $347-352$.

18. van Schayck GP, Loozen JMG, Wagena E, Akkermans RP, Wesseling GJ. Detecting patients at a high risk of developing chronic obstructive pulmonary disease in general practice: cross sectional case finding study. BMJ. 2002;321(324):1370-1375.

19. National Institute for Clinical Excellence (NICE). Chronic obstructive pulmonary disease: national clinical guideline for management of chronic obstructive pulmonary disease in adults in primary and secondary care. Thorax. 2004;59(Suppl 1):1-232.

20. Peces-Barba G, Barbera JA, Agusti A, et al. Diagnosis and management of chronic obstructive pulmonary disease: joint guidelines of the Spanish Society of Pulmonology and Thoracic Surgery (SEPAR) and the Latin America Thoracic Society (ALAT). Acta Bronchopneumol. 2008;44: 271-281.
International Journal of COPD

\section{Publish your work in this journal}

The International Journal of COPD is an international, peer-reviewed journal of therapeutics and pharmacology focusing on concise rapid reporting of clinical studies and reviews in COPD. Special focus is given to the pathophysiological processes underlying the disease, intervention programs, patient focused education, and self management

\section{Dovepress}

protocols. This journal is indexed on PubMed Central, MedLine and CAS. The manuscript management system is completely online and includes a very quick and fair peer-review system, which is all easy to use. Visit http://www.dovepress.com/testimonials.php to read real quotes from published authors. 